\title{
Una mirada transnacional
}

A Transnational Gaze [1]

\author{
Peggy Levitt \\ Wellesley College, Estados Unidos \\ plevitt@wellesley.edu
}

\section{Resumen}

\section{Resumen}

En los 10 años que tiene de haberse fundado esta revista[2], importantes cambios demográficos han dado lugar a transformaciones en los estudios sobre migración. Desde esta perspectiva, las preguntas que se hacen los estudiosos de la migración junto con las herramientas de análisis y la metodología que utilizan para responderlas se han modificado drásticamente. En este ensayo se asume una mirada desde una perspectiva idiosincrásica para anlizar estos cambios y se propone un rumbo a seguir en el futuro. El estudio se concentra en las ventajas analíticas de utilizar una perspectiva transnacional para el estudio de la migración, en la importancia de tomar en cuenta el espacio y la magnitud de nuestro trabajo, y en situar de nuevo la cultura en el centro de nuestros debates. Así mismo se destacan las oportunidades que las intersecciones interdisciplinarias nos brindan para que nuestro campo avance en una nueva y más productiva dirección.

Palabras clave: transnacional, escala, migración, simultaneidad, inmigración. 
Peggy Levitt. Una mirada transnacional.

Autoctonía Revista de Ciencias Sociales e Historia, Vol. II, Nº1

\section{Introducción}

En la década transcurrida desde que se fundó esta revista[3], importantes cambios demográficos han dado lugar a transformaciones en los estudios sobre migración. En los Estados Unidos, más y más recién llegados se están mudando a destinos no tradicionales tanto urbanos como rurales, la "nueva" segunda generación de migrantes está llegando a la mayoría de edad, y el poder político y económico de la nación está disminuyendo. En Europa, los países -no acostumbrados o no dispuestos a reconocer su diversidad- están lidiando con el asentamiento permanente y la integración de los recién llegados. Allí, la segunda generación también está creciendo, y el otro religioso (musulmanes principalmente) desafía directamente a un continente que insiste obstinadamente en su secularidad. La migración sur-sur también es cada vez más común, particularmente en lugares como el sur de África, el Cono Sur de América Latina y el Sudeste Asiático.

En este contexto, las preguntas que plantean los estudiosos de la migración, junto con las herramientas analíticas y metodológicas que utilizamos para responderlas, se han modificado en forma drástica. En este ensayo asumo una mirada desde una perspectiva idiosincrásica para anlizar estos cambios y propongo indicaciones para el futuro. La opinión que aquí se presenta es bastante personal y no constituye un estado del arte sistemático en esta área. Por el contrario, me concentro en las ventajas analíticas de utilizar una perspectiva transnacional para el estudio de la migración, en la importancia de tomar en cuenta el espacio y la magnitud de nuestro trabajo, junto con situar de nuevo a la cultura en el centro de nuestro diálogo. De igual modo, se destacan las oportunidades que las intersecciones interdisciplinarias nos brindan las que, una vez alcanzadas, podrían hacer que nuestro campo avance en direcciones nuevas y más productivas.

\section{Una mirada transnacional}

La mayoría de los estudiosos reconocen hoy en día que los migrantes contemporáneos y sus predecesores a menudo mantienen vínculos con sus países de origen mientras llegan a formar parte de los países en donde se asientan. De hecho, la migración nunca ha sido un proceso unidireccional de asimilación hacia un melting pot[4] o hacia un "salad bowl" [5], ha sido mas bien un proceso en el que los migrantes, en diversos grados, se integran de manera simultánea en múltiples sitios y estratos de los campos sociales transnacionales en los que viven. Cada vez más, la vida social ocurre en las fronteras, incluso cuando el poder político y cultural de la nación permanece sólido.

Estos desarrollos en la investigación sobre migración igualan los debates en otros campos. La historia se ha alejado de las comparaciones nacionales simplistas para reconceptualizarse como el estudio de las interacciones regionales, lo que se puede ver en sitios como $E l$ Atlántico Negro (Gilroy, 1993) o the Indian Ocean Rim (Bose, 2006). Keohane y Nye (1971) argumentaron hace décadas que las relaciones internacionales debían repensar sus categorías conceptuales básicas para incluir aquellas transfronterizas entre diferentes actores no estatales y subnacionales.

Como resultado, en el mundo de hoy, no es suficiente el estudio de la dinámica social mediante la comparación de experiencias dentro o a través de unidades sociales, supuestamente limitadas o cerradas. Los Estudios Transnacionales (ET) adelantan la afirmación de que lo global, lo regional, lo nacional y lo local pueden analizarse desde un punto de vista metodológico, teórico y epistemológico transnacional (Khagram y Levitt, 2007). En contraste con las perspectivas tradicionales, las cuales observan lo transnacional como algo que ocurre entre lo nacional y lo global, los ET proponen otra opción. Los grupos sociales catalogados 
Peggy Levitt. Una mirada transnacional.

Autoctonía Revista de Ciencias Sociales e Historia, Vol. II, Nº1

como delimitados y cerrados, hoy se entienden como espacios sociales influenciados, integrados y constituidos de forma transnacional que interactúan entre sí. El mundo está compuesto por múltiples conjuntos de campos sociales interrelacionados y que se superponen de manera dinámica, que crean y dan forma a estructuras, actores y procesos, en apariencia confinados y acotados. Dichos grupos, o conjuntos supeditados de elementos materiales y sociales, que incluyen el conocimiento, la tecnología y las categorías ontológicas, así como los objetos y las prácticas, se unen y se componen de elementos que circulan dentro de estos espacios transnacionales.

Por lo tanto, términos como "transnacional", "transnacionalismo" y "transnacionalidad" serían en parte conceptos equivocados en cuanto impliquen sólo una preocupación por la dinámica en o más allá de las naciones y estados o dentro del sistema estatal nacional. Dichos términos significan mucho más. Una óptica o mirada transnacional comienza con un mundo sin fronteras y examina empíricamente los límites y las fronteras que surgen en momentos históricos particulares, las relaciones de poder que los crean y su vínculo con áreas y procesos ilimitados. Esta visión no subestima la unidad espacial de análisis adecuada; de hecho, un componente clave de este enfoque es examinar la amplitud territorial y el alcance de cualquier fenómeno social sin suposiciones previas. Tampoco privilegia lo global o lo local, sino que trata de mantener estos niveles de experiencia social, y todos los demás existentes entre ellos, en un diálogo recíproco, prestando especial atención a cómo sus múltiples emplazamientos y capas interactúan y se informan el uno al otro.

Los estudios de migración transnacional comienzan identificando los parámetros y niveles de los ámbitos sociales relevantes dentro de los cuales tiene lugar la migración. Los campos sociales constituyen un conjunto de múltiples redes interconectadas de relaciones sociales a través de las cuales las ideas, las prácticas y los recursos se intercambian, organizan y transforman de manera desigual (Levitt y Glick Schiller, 2004). Son redes multidimensionales, que abarcan interacciones estructuradas de diferentes formas, profundidad y amplitud. Los ámbitos sociales nacionales son aquellos que permanecen dentro de las fronteras del país, mientras que los transnacionales conectan a los actores a través de las relaciones directas e indirectas más allá de las fronteras.

Cualquier estudio, ya sea sobre la migración de personas o de culturas, debe comenzar por determinar el nivel y la intensidad de la conexión con los actores y las instituciones ubicadas en otros sitios y niveles del ámbito social relevante. Debe tratar a individuos y grupos no como contenedores cerrados anidados en emplazamientos locales, sino como sitios potenciales de agrupamiento y convergencia, los que, una vez constituidos, circulan y re-circulan, cambiando constantemente a medida que se desplazan. La configuración resultante no es puramente local o global, sino que está anidada en escalas múltiples e interrelacionadas de gobernanza regional, nacional y global, cada una con su propia lógica y repertorios de recursos institucionales y discursivos.

\section{Cambio de suposiciones y expectativas}

¿Qué nos revela el estudio de la migración bajo una óptica transnacional?

Una cosa es que el mundo se caracteriza cada vez más por la movilidad y el flujo constante, más que por la estabilidad y el arraigo (aunque esto no significa que todas las personas puedan hacerlo o que se movilicen por igual). Esta situación va en contra del argumento de muchos informes, tanto académicos como populares, que no solo sufren del nacionalismo metodológico, o la expectativa de que las personas y las organizaciones 
Peggy Levitt. Una mirada transnacional.

Autoctonía Revista de Ciencias Sociales e Historia, Vol. II, Nº1

respeten de forma obediente las fronteras nacionales, sino también de la suposición errada de que la inmovilidad y las limitaciones son la norma; cuando, de hecho, las personas y la cultura circulan de manera amplia.

Necesitamos contar con métodos más precisos para estudiar a las personas y la cultura migrantes junto con la relación que se produce entre ellas. De igual modo, necesitamos preguntarnos cómo cambian las presuposiciones sobre la democracia, la identidad y la participación si la movilidad se considera como un punto central en la vida contemporánea. ¿Cómo cambiaría nuestra comprensión del contrato social entre el estado y la ciudadanía, si reconociéramos que la salud, la generación de ingresos, la vida familiar y la educación a menudo se producen fuera de la jurisdicción nacional?

Tomar en serio a la movilidad abre el diálogo para incluir diferentes tipos de movimiento, y diferentes intensidades y frecuencias de contacto.[6] Los turistas, los misioneros, los peregrinos, los trabajadores migratorios y los miembros de pandillas también se mudan. Ante esta situación, cabe preguntarse sobre la manera en la que se diferencia el impacto de la migración de otras formas de movimiento que involucran distintos niveles y fuerza de contacto entre los residentes y los recién llegados. ¿De qué forma cambia el "efecto del encuentro" cuando alguien es un turista o viajero en lugar de un inmigrante residente? ¿Cómo las diferentes filosofías nacionales de integración y los regímenes de gestión de la diversidad (o, en otras palabras, las suposiciones nacionales sobre las diferencias étnicas y religiosas y cómo debiesen gestionarse) influyen en la naturaleza y el efecto de estas interacciones?

Un segundo aspecto que una óptica transnacional pone de manifiesto es que los estudios en migración pueden tratar tanto sobre los no inmigrantes como acerca de las personas que se mudan. En algunos casos, los migrantes y los no inmigrantes, aunque separados por la distancia física, continúan ocupando el mismo espacio sociopolítico. Debido a que los bienes, las personas, el dinero y las remesas sociales circulan en forma regular, incluso los individuos que nunca se trasladan están influenciados por valores y prácticas de cerca y de lejos.

El hecho de ver a los inmigrantes y no inmigrantes ocupar el mismo espacio social desafía el significado de la integración. La experiencia del inmigrante no es un viaje lineal e irreversible de una pertenencia a otra. Por el contrario, los migrantes oscilan hacia adelante y hacia atrás entre el envío, la recepción y otras orientaciones en diferentes etapas de sus vidas. En cuanto sus vidas se fundamenten más en sistemas legales, de atención de la salud y de pensiones en ambos lados de la frontera, es más probable que continúen viviendo vidas transnacionales. Un número cada vez mayor de recién llegados no se asimilará por completo ni se mantendrá concentrado de manera total en sus países de origen, sino que elaborará una combinación de los dos contextos, variando durante el ciclo de vida. Sus vidas estarán posibilitadas y limitadas por múltiples repertorios e instituciones culturales. La movilidad social y la inclusión en un nuevo lugar, por tanto, están fuertemente conectadas con la condición social y la inclusión en el lugar anterior.

Sin embargo, existe una diferencia entre las formas de ser y las formas de pertenencia en un campo social transnacional (Levitt y Glick Schiller, 2004). Las formas de ser se refieren a las relaciones y prácticas sociales reales en las que se involucran los individuos en lugar de las identidades asociadas a esas acciones. Los individuos pueden integrarse en un ámbito social, pero no identificarse con alguna etiqueta o política cultural vinculada a esa área. Pueden desconocer o rechazar la etiqueta de "diáspora" que les ofrecen sus pares, la academia o los estados de origen, o pueden 
Peggy Levitt. Una mirada transnacional.

Autoctonía Revista de Ciencias Sociales e Historia, Vol. II, Nº1

adoptarla de manera activa. Por otro lado, hay quienes tienen pocos vínculos sociales con personas de su país de origen, pero que, no obstante, se identifican con él. Debido a que estas personas tienen alguna conexión con una forma de pertenencia, a través de la memoria, la nostalgia, la competencia cultural o la imaginación, también forman parte de este ámbito social y expresan su identificación con él. Si las personas se involucran en relaciones y prácticas sociales que cruzan las fronteras como una característica habitual de la vida cotidiana, ellos manifiestan una forma de ser transnacional. Cuando las personas se identifican explícitamente con un grupo que cruza fronteras, también expresan una forma transnacional de pertenencia. Estas dos experiencias no siempre van juntas.

Al diferenciar entre las formas de ser y de pertenecer, se enfocan de manera más nítida las innumerables elecciones de identidad que enfrentan los migrantes y los no inmigrantes. No podemos suponer que las personas adoptan automáticamente las etiquetas étnicas o nacionales, situación que Glick Schiller y Caglar (2008) denominaron "etnicidad metodológica". Más bien, ellos eligieron cómo ser y pertenecer, y esa opción está hecha para ellos, basada no solo en sus países de origen o de acogida, sino también en sus conexiones con personas de su mismo origen étnico, profesionales y correligionarios de todo el mundo. Pueden atravesar múltiples caminos hacia la integración simultánea en varios ámbitos destacados en todo el mundo.

Los grupos étnicos, nacionales, religiosos y profesionales pueden caracterizarse por altos niveles de variación intragrupo (Werbner, 2000). Tanto los altamente calificados como los que apenas saben leer y escribir, los de piel oscura y los de piel clara adoptan la etiqueta de "indio". Dentro de él se encuentran otras subidentidades, incluida la región o el estado de una persona, su casta y subcasta, su comunidad religiosa, la ciudad o distrito donde vive. La misma persona que se preocupa poco por su región o estado puede sentirse profundamente comprometida con su tierra natal porque es un miembro devoto de una comunidad religiosa. El hecho de que los individuos manejen esas identidades diversas de manera interna hace comprender los riesgos analíticos de considerar a las comunidades étnicas como la "elección" dominante y automática, o de tomar cualquier grupo como un conjunto monolítico dado (Levitt, 2007).

Al poner en tela de juicio los parámetros y la amplitud de los ámbitos sociales dentro de los cuales tiene lugar la migración, una óptica transnacional genera un conjunto variado de inquietudes sobre la integración y la identidad, además de ofrecerles un grupo diferente de respuestas.

\section{Localidad y escala}

Otra dirección prometedora en los estudios de migración es su mayor enfoque a las cuestiones de espacio y lugar. Si bien la relación entre la acumulación de capital global, la reestructuración económica y los movimientos de personas es ampliamente reconocida, a menudo se pasan por alto las cuestiones de cómo y por qué esos procesos convergen de manera distinta en diferentes lugares (Glick Schiller y Caglar, 2009).

En los Estados Unidos, los investigadores por lo general toman en consideración el espacio cuando discuten contextos de recepción. Portes y Rumbaut (2006) enfatizaron la influencia de los gobiernos receptores, las características del mercado laboral del país de acogida y las particularidades de las comunidades étnicas en la configuración de los contextos de acogida. Jeffrey Reitz (2002) hizo hincapié en las relaciones étnicas y raciales entre la población de acogida, las diferencias en los mercados laborales y las instituciones relacionadas, el impacto de las políticas y los programas gubernamentales, y la 
Peggy Levitt. Una mirada transnacional.

Autoctonía Revista de Ciencias Sociales e Historia, Vol. II, Nº1

naturaleza cambiante de las fronteras internacionales. Además, el autor argumentó que las características de las sociedades de acogida influyen tanto o más en la integración de los inmigrantes que sus características individuales.

Trabajos más recientes ven la integración exitosa de inmigrantes como el producto de las oportunidades y barreras que ellos enfrentan en la comunidad receptora. La integración es un proceso fluido, basado en factores individuales y de nivel comunitario. Además del contexto, estos investigadores también observan cómo las culturas institucionales y las políticas nacionales y locales influyen en las trayectorias de movilidad (Fix y Zimmerman, 2000; Waldinger, 2001). Otros puntos importantes de destacar incluyen las percepciones sobre los recién llegados y la apertura, o resistencia, a la inmigración (Padín, 2005; Bloemraad, 2006), las representaciones mediáticas de los inmigrantes (Chavez, 2001; Padín, 2005) y la movilización política local (Bloemraad, 2006).

Los académicos también están trabajando de forma ardua para sacar a la luz las características de las nuevas geografías de inmigrantes no tradicionales (Massey, 2008; Singer et al., 2008). Examinan las condiciones bajo las cuales los inmigrantes revitalizan o perjudican la economía regional (Singer et al., 2008; HernándezLeón y Zúñiga, 2005; Godzniak y Martin, 2005; Smith y Furseth, 2006). Sin embargo, gran parte de esta investigación no presta suficiente atención a cómo se anidan nuevos contextos de recepción en jerarquías geopolíticas más grandes. Los contextos de recepción generalmente se consideran nacionales, aunque la integración de inmigrantes, así como la promulgación de normas y las respuestas de la comunidad a los inmigrantes, varían considerablemente en los espacios físicos y políticos dentro de las naciones y entre ellas.

En Europa, el espacio es una parte clave de las discusiones sobre "la ciudad como contexto" (Glick
Schiller, Caglar y Guldbrandsen, 2006). En la década de 1990, un pequeño grupo de académicos había observado cómo el tamaño, la posición y el panorama político afectan la forma en que los migrantes se asentaron y se integraron de forma política a determinadas ciudades. Al igual que sus contrapartes estadounidenses, esta investigación, en gran medida, no abordó cómo la reestructuración económica mundial reposiciona lugares específicos y dirige a los migrantes a establecerse en el lugar donde lo hacen. El estudio de las ciudades globales fue un paso en esta dirección (Eade, 1997; Sassen, 2001). Estos investigadores llamaron la atención sobre la brecha entre los espacios geográficos y sociales que resultó de los efectos desiguales de la globalización. Ciudades específicas se restaron de la jerarquía mundial para funcionar casi de forma independiente del contexto nacional. La mayoría de este trabajo, sin embargo, no estableció una conexión entre estos procesos y la integración de inmigrantes.

La noción de 'escala' ayuda a captar cómo las estructuras, vidas y políticas urbanas están integradas en una gama de jerarquías político-económicas (Glick Schiller y Caglar, 2009). La reestructuración económica mundial reposiciona a las localidades en jerarquías de poder económico y político. Pero no es solo el capital el que se muda. Cuando los migrantes se mudan, sus modos de integración están fuertemente vinculados a este reordenamiento más amplio de los ámbitos de poder interestatal, regional, nacional y global (Glick Schiller, Caglar y Guldbrandsen, 2006; Glick Schiller y Caglar, 2009). Por otra parte, el éxito de la integración no es solo una función de la posición cambiante de determinadas localidades en el contexto de la globalización, sino que también está ligado a la relación cambiante entre las localidades y los estados. La intervención y las actividades del estado están diferenciadas de manera institucional y geográfica. Los Estados están influyendo en la integración de 
Peggy Levitt. Una mirada transnacional.

Autoctonía Revista de Ciencias Sociales e Historia, Vol. II, Nº1

los inmigrantes cuando se persiguen estrategias de desarrollo económico, cuando se diseñan políticas de reasentamiento de refugiados, cuando se dirigen recursos a zonas particulares (como la elección de la capital de estado) o cuando se construyen carreteras en determinados emplazamientos. La escala, por consiguiente, implica no solo recalibrar la relación entre lo global y lo local, sino también entre lo municipal, regional y nacional.

Las ciudades también poseen recursos culturales particulares, basados en sus posiciones geopolíticas, los que utilizan de maneras específicas. Brettell (2005) enfatiza la importancia de un conjunto dominante de valores o un ethos urbano al configurar la integración de los inmigrantes. Glick Schiller y Caglar (2009) destacan el discurso público como un punto clave de conexión entre la migración y la teoría de la escala. Los autores argumentan que la diversidad cultural es un factor importante en la lucha competitiva entre ciudades. Los inmigrantes pueden constituir bienes negociables en el lugar de asentamiento, incluso posibilitando que algunas ciudades se reposicionen geopolíticamente. En su estudio acerca de Portland, Maine y Danbury, Connecticut, Cadge et al. (2010) hallaron que la forma en que estas ciudades crearon e implementaron sus estructuras culturales[7] ayudó a explicar algunas de las variaciones en la incorporación de inmigrantes. Su historia de dos ciudades destacó la importancia de incorporar la cultura y la escala en las discusiones sobre el espacio y los contextos de recepción.

\section{Recuperando la cultura}

La mayoría de los debates sobre la migración y el desarrollo privilegian lo económico en detrimento de lo social. Las remesas de los emigrantes y las transferencias filantrópicas registradas de forma oficial ascendieron a 338 mil millones de dólares estadounidenses en el año 2008, casi el doble de la Cooperación Oficial para el Desarrollo (Banco Mundial, 2009). Las agencias de ayuda internacional y los gobiernos están trabajando en forma ardua diseñando políticas para aprovechar estos recursos y canalizarlos con un propósito determinado (Wilmaladharma et al., 2004). En este contexto, no es de extrañar que muchos académicos y legisladores elogien las remesas como la próxima panacea del desarrollo.

Pero la economía no lo es todo. La cultura permea todos los aspectos del desarrollo económico como un desafío y una oportunidad. Las ideas y prácticas viajan en respuesta a la migración, la que, a su vez, permite a las personas moverse y crear nuevas formas de afiliación y pertenencia. La cultura también influye de forma considerable en cómo se establecen los objetivos de desarrollo, qué políticas se ponen en marcha para lograrlos y con qué nivel de éxito se logran. En este sentido, al privilegiar lo económico, los investigadores y los legisladores pasan por alto un importante instrumento potencial y no reconocen las posibles barreras al desarrollo (Rao y Woodcock, 2007).

Por consiguiente, otro movimiento analítico de relevancia es devolver la cultura a los debates migratorios. Hacerlo requiere no solo observar la "migración de la cultura", o la religión, las ideas, o las actividades artísticas, sino también ver la migración como un acto cultural. Debido a que las identidades $\mathrm{y}$ acciones de los migrantes son ricas en significado cultural y social, centrarse solamente en las redes sociales, los cargos o las actividades es insuficiente. No es el qué o cuándo estas prácticas o identidades puedan ser culturales, sino más bien que ellas son culturales de manera intrínseca.

Los investigadores de la asimilación de los inmigrantes en gran medida también han eludido la cultura porque se preocupan, de forma principal, por su integración 
Peggy Levitt. Una mirada transnacional.

Autoctonía Revista de Ciencias Sociales e Historia, Vol. II, Nº1

más que por la forma en que se abandonan o adoptan los elementos culturales. Cuando la investigación cambió "más allá del crisol cultural" y reconoció que la diversidad perduraría como una "salad bowl" o un "mosaico glorioso", la cultura se incluyó en la etiqueta de "etnicidad". Las influencias culturales, aunque reconocidas en todas partes, fueron caracterizadas como valores étnicos, costumbres y preferencias y, como la etnicidad se consideraba cada vez más opcional (Waters, 1990), simbólica (Gans, 1979), o en decadencia (Alba, 1990), la cultura también quedaba relegada a un papel secundario. Por consiguiente, cuando se tuvo en cuenta, la cultura figuraba solo en un nivel macro. Los teóricos de la modernización y sus descendientes argumentaron que el desarrollo simplemente se alcanzaría si comprendiéramos la cultura acertivamente. Desde el libro de Edward Banfield de 1958, The Moral Basis of a Backward Society (1967) hasta Lawrence Harrison y el libro de Samuel Huntington del año 2000, Culture matters: How Values Shape Human Progress, los autores han argumentado que el tipo de cultura equivocado relega de forma permanente a los países o regiones al retraso. Los conceptos "anticuados" y "poco consistentes" que utilizan muchos de estos teóricos no reconocen la imagen multidimensional y compleja que surge cuando se utilizan atributos heterogéneos para comprender la cultura (Lamont y Small, 2008).

Sin embargo, un cambio radical está en marcha. Lourdes Arizpe (2004) escribió "No es la cultura la que está incrustada en el desarrollo. Es el desarrollo el que está incrustado en la cultura". Amartya Sen (1999) también argumentó que la cultura es una parte constitutiva del desarrollo. Si el progreso se trata de mejorar el bienestar y liberar mentes, entonces debe considerar la literatura, las bellas artes y todo lo demás que posibilite el bienestar de la población. Arjun Appadurai (2004) enfatiza la relación entre la cultura y la reducción de la pobreza al señalar que "en la cultura las ideas sobre el futuro y sobre el pasado están arraigadas y nutridas. La capacidad de aspiración es una capacidad cultural. A menudo nos enfocamos en la cultura como una especie de 'pasado', mientras que el desarrollo se expresa en términos de progreso y futuro". Para que la cultura se incorpore con éxito a la ecuación de desarrollo, esa brecha debe ser superada.

Los científicos sociales han luchado por definir la cultura durante décadas. Arizpe (2004: 164) la describe como

un flujo de significados que los seres humanos crean, mezclan e intercambian. Las culturas son filosofías de vida que mantienen unidas todas las prácticas sociales que crean y mantienen a un ser humano capaz y creativo. Dichas prácticas también mantienen a las sociedades unidas, equilibradas y funcionando adecuadamente. En este sentido, las culturas funcionan de manera principal como sistemas reguladores que ayudan a mantener los sentimientos y las acciones de las personas dentro de los límites del comportamiento institucionalmente aceptable. Cuando tales sistemas son ignorados en el desarrollo, tienden a generar un comportamiento antisocial.

La socióloga Ann Swidler (1986) propuso la noción de cultura como un juego de herramientas. Desde su perspectiva, la cultura es una maleta cambiante y dinámica de trucos que las personas usan para resolver problemas e interpretar sus mundos. Estas constituyen las herramientas cognitivas, simbólicas y lingüísticas que existen en las cabezas de las personas y los rituales, relaciones y prácticas que utilizan para expresarlas. Para Lamont y Small (2008), la cultura constituye las estructuras, los repertorios, las narraciones, el capital 
Peggy Levitt. Una mirada transnacional.

Autoctonía Revista de Ciencias Sociales e Historia, Vol. II, Nº1

cultural y los límites simbólicos que la gente utiliza y a los cuales los académicos deben prestarle más atención para comprender mejor la relación entre la cultura y la pobreza.

No me es posible solucionar estos debates aquí, ya que ese es trabajo de los antropólogos, pero si me es viable establecer lo que no es la cultura. La cultura no es un sistema cohesivo. Sus partes componentes no deben tener sentido entre sí, ni las personas que pertenecen al mismo grupo cultural necesariamente incluyen herramientas similares en su maleta. No existe el llamado código cultural porque el paquete cultural existente en un momento dado surge de una historia y economía política en particular (Besserer, 2003). El "código" varía en respuesta a las cambiantes circunstancias sociohistóricas. La creencia en el "holismo cultural" no solo es errónea sino dañina. Es la base de las predicciones del choque de civilizaciones porque los escritores que ven la cultura de esta manera suponen que los paquetes que importan los migrantes chocarán de forma automática con los ya existentes.

Según García Canclini (1995), a medida que las industrias culturales globales se apropian de las tradiciones, entran en circuitos internacionales de comunicación y se mueven de un lado a otro junto con los migrantes transnacionales. Así ambos se "desterritorializan", o se desvinculan de sus localidades de origen, y se "reterritorializan", o se vuelven a localizar, mezclar y son puestas en yuxtaposición con el discurso y las prácticas modernas y posmodernas. El resultado final es tiempos y espacios mixtos e híbridos, nuevas configuraciones híbridas que transforman la cultura y la esfera pública al permitir que surjan renovados individuos e identidades y voces colectivas. Asimismo, la cultura no es un ámbito social separado, sino que se extiende a todos los aspectos de la vida social. Cómo influye en el ámbito económico es evidente en cómo la ética, las tasas de iniciativa empresarial y la aversión al riesgo varían entre los grupos. Por ejemplo, una gobernanza democrática factible solo es posible cuando una comunidad tiene experiencia previa con la participación y el debate público (Sen, 1999).

En resumen, la cultura no puede eliminarse de manera artificial de otras esferas sociales, ni la economía ni la política pueden privarse de la cultura. Igualmente, la cultura no se puede separar del sistema. Todas las migraciones están integradas en condiciones estructurales determinadas, relaciones de poder y, en particular, contextos socioeconómicos de recepción (Besserer, 2003). La cultura y la estructura son mutuamente constitutivas. Lo que realmente implican las categorías sociales como la familia, el hogar o la membresía, y cómo se establecen, se desarrolla en respuesta a determinadas circunstancias económicas y sociales.

\section{El traslado más allá de la cultura como producto}

Una vez que reconocemos que la pobreza de los inmigrantes y el desarrollo comunitario en las sociedades de origen son dos caras de la misma moneda, y que la cultura es una parte importante de su alquimia, surgen dos inquietudes. La primera se refiere a dónde debemos buscar la cultura y qué formas posibles puede tomar. La segunda apunta a cómo puede utilizarse la cultura de manera efectiva, como una pieza central de este rompecabezas, y cuáles son los costos y beneficios de un enfoque de este tipo.

La mayoría de las políticas tratan la cultura como un producto, un objeto material y concreto, tal como un baile, una pieza de música, arte popular o una tradición narrativa que se transforma, reinventa o se ve amenazada con la migración. La cultura se aprecia como algo para reanimar y preservar, resucitar y reforzar, un bien incondicional para ser protegido a toda costa. 
Peggy Levitt. Una mirada transnacional.

Autoctonía Revista de Ciencias Sociales e Historia, Vol. II, Nº1

Además, se considera que obstaculiza la integración o el desarrollo, ya que determinados grupos poseen rasgos culturales negativos que les impiden aprender a trabajar duro, confiar en extraños o gobernar de manera efectiva. También la cultura se percibe como una herramienta de empoderamiento, dado que cuando a un grupo se le permite expresar su cultura, se posibilita su reclamo por un lugar en la nueva sociedad.

Esta visión es problemática por varias razones. Primero, los productos culturales no están escritos en piedra. No se conservan intactos ni se transforman por completo cuando las personas se trasladan, pero sí experimentan alguna combinación. Por otro lado, las relaciones de poder que rodean la expresión y representación de los objetos culturales también cambian. En consecuencia, ¿quién debería decidir qué baile o canción representa a un grupo supuestamente homogéneo? Una idea aún más equivocada, considerando los argumentos que ya he presentado, es la suposición de que la cultura es un todo separado y empaquetable que se puede sacar y analizar alejado de las relaciones sociales.

Un enfoque más fructífero considera la cultura como una extensión de todas las relaciones y formas sociales que afectan todos los aspectos de la integración de inmigrantes y del desarrollo de la comunidad de origen. Las celebraciones del Día del Santo Patrono son un ejemplo de un espectáculo cultural profundamente modelado por las influencias culturales. Muchos migrantes latinoamericanos regresan a sus comunidades de origen para su celebración anual del día del santo patrono. Incluso si no pueden viajar, aportan tiempo, dinero y recursos para honrar a sus comunidades, a menudo organizando celebraciones simultáneas donde sea que estén. Algunas comunidades mexicanas incluso envían un sacerdote como representante del santo de su pueblo para asistir a sus festividades en Nueva York (Rivera Sanchez, 2004). Al extender la fiesta de México a los Estados Unidos, la comunidad extiende sus límites de pertenencia más allá de lo físico. Al mismo tiempo, reclama espacio y reconocimiento en la ciudad de Nueva York.

En lugar de ver la cultura solo como un producto, también se puede entender como un proceso. Cuando las personas participan y realizan representaciones culturales, también las crean y reinventan. De ese modo, los eventos culturales son situacionees de trabajo limítrofe durante los cuales las comunidades afirman quiénes son ante sus miembros y terceras personas de todo el mundo.

Por ejemplo, un mayordomo masculino, o un benefactor, es un rol asociado al respeto y responsabilidad, por lo que generalmente patrocina las celebraciones del Día del Santo Patrono. Para conservar la ciudadanía en muchas comunidades indígenas mexicanas, los emigrantes aún tienen que cumplir con ciertas obligaciones colectivas, a pesar de que ya no viven en sus hogares. Ya que tantos miembros de la comunidad viven en los Estados Unidos, quedan muy pocos hombres para patrocinar la celebración. Como resultado, algunas comunidades reescriben las reglas, y permiten que aquellos que viven en el extranjero sean mayordomos, los cuales delegan sus responsabilidades cotidianas a un familiar o amigo no inmigrante. Al hacerlo, la comunidad señala que su territorio se ha expandido para incluir a las personas que viven en los Estados Unidos. De este modo, se crean nuevas formas para que las personas cumplan con sus obligaciones de ciudadanía y puedan seguir perteneciendo a su comunidad. La membresía sin residencia no solo es una posibilidad, sino también una necesidad.

La Fiesta Patronal es un espectáculo para para sus miembros y personas ajenas, es decir, es la representación de la comunidad para sí misma y para el mundo exterior. Es así como se crean nuevos tipos de grupos a través de actividades culturales (Gil et 
Peggy Levitt. Una mirada transnacional.

Autoctonía Revista de Ciencias Sociales e Historia, Vol. II, Nº1

al., 2005). La Hora Mixteca, un programa en Radio Bilingüe, una estación que sirve a los pueblos indígenas en México y en el suroeste de los Estados Unidos, ayudó a crear una comunidad pan-indígena. Cuando los oyentes escucharon por primera vez la programación en su propio idioma, se sintieron parte de la nación mexicana de una manera como nunca antes se habían sentido. Al escuchar su identidad indígena compartida y transmitida para ellos, también sintieron un sentido de pertenencia a una comunidad pan-étnica que abarca a miembros en México y Estados Unidos. Escuchar este programa también reforzó los lazos generacionales porque los miembros de la familia, ya sea en México o en California, podían hacerlo de forma "conjunta" (Informe NATC 2004a y 2004b).

La Fiesta Patronal es también una instancia donde el género se redefine. Las mujeres pueden y, en algunos casos, se les exige que asuman funciones de liderazgo de las que antes estaban excluidas, por la simple razón de que no hay suficientes hombres para ocupar dichos puestos. Esto les permite acceder a los círculos de poder $\mathrm{y}$ de toma de decisiones que estaban en el pasado fuera de su alcance. Al mismo tiempo, cuando los migrantes vuelven a vivir o a visitar su país de origen, traen consigo diferentes formas de manejar el concepto de género y la familia, en función de sus experiencias en el extranjero. Smith (2005) escribe sobre los conflictos en torno al género, que surgen entre los hombres y las mujeres mexicoamericanos jóvenes de segunda generación, cuando visitan sus pueblos ancestrales. Lo que se considera un comportamiento aceptable en Nueva York es inapropiado en México. El hermano que nunca pensó dos veces en que su hermana saliera sola en Manhattan, siente que es responsable de controlarle el comportamiento en México. Al menos dos grupos de normas compiten entre sí, y las personas y comunidades deben determinar cómo resolver el conflicto.

Algunos inmigrantes quieren ser el benefactor de la celebración del día del patrono porque quieren retribuir a su comunidad. En cambio, otros buscan esta posición como una plataforma desde la cual mostrar su mejor nivel de vida. Gastan tanto dinero tratando de demostrar su posición, que el patrocinio del festival aumenta más allá de los recursos con los que dispone la mayoría de los no inmigrantes. Como cada nuevo mayordomo alberga una celebración aún más lujosa que la anterior, las aspiraciones de consumo exageradas de los lugareños aumentan aún más. Lo que las hijas e hijos oriundos de ese lugar deben hacer para señalar su lealtad está más allá de lo que la mayoría de los residentes, migrantes o no, sienten que pueden o deberían ser capaces de hacer. Su valor se mide por sus contribuciones financieras más que por su autoridad moral o liderazgo. Sin embargo, nadie parece estar dispuesto o ser capaz de detener este círculo vicioso. Moderar la celebración sugeriría que la comunidad prosperó en menor grado de lo que se había hecho creer o que los beneficios de la migración no siempre superan sus sacrificios.

Por otra parte, la migración obliga a las comunidades a revisar sus narrativas sobre el progreso y el éxito, sobre cuáles deberían ser los objetivos del desarrollo y la integración. Dado que los migrantes en general ganan más dinero que los no inmigrantes, suelen tener una voz más fuerte en las discusiones sobre lo que constituye el desarrollo. Sus motivos para contribuir a la comunidad y lo que esperan lograr a través de sus contribuciones pueden ser cada vez más distintos de aquellos de las personas que se quedan atrás. En este sentido, los migrantes ven a su comunidad como un lugar para vacacionar, retirarse $\mathrm{y}$, finalmente, morir, mientras que los no inmigrantes lo ven como un sitio donde necesitan trabajo y atención médica. Los miembros migrantes desean construir funerarias, campos de juego y plazas, en cambio los no inmigrantes quieren construir escuelas y clínicas. Un debate paralelo emerge frente al activismo comunitario en el país de asentamiento. Mientras que algunos miembros de la 
Peggy Levitt. Una mirada transnacional.

Autoctonía Revista de Ciencias Sociales e Historia, Vol. II, Nº1

comunidad abogan por un cambio de enfoque hacia la integración social y política en los Estados Unidos, otros temen que esto les restará valor a sus esfuerzos por ayudar a las personas en sus países de origen.

La cultura es también un régimen de normas, poder y estatus que permite y restringe el comportamiento (Appadurai, 2004). Significados, símbolos y narrativas hacen posible la producción cultural pero también la restringen, porque los repertorios en los que se basa dicha producción solo contienen ciertos elementos. Los términos de reconocimiento y posibilidad que subyacen a estos regímenes tienen que modificarse para que ocurra cualquier tipo de cambio fundamental.

Una mirada cercana a los comportamientos ostensiblemente económicos revela cómo funcionan los regímenes culturales. Algunos migrantes envían remesas a amigos y familiares como una forma de seguro social. Mantienen las relaciones con las personas en casa, por si las cosas van mal y tienen que regresar a su país. Bryceson y Vuorela (2002) utilizan el término "relativizar" para describir cómo las personas establecen, mantienen o descuidan vínculos con familiares específicos o parientes ficticios. Eligen estratégicamente qué conexiones enfatizar y cuáles dejar pasar en función de lo que creen que serán sus necesidades futuras.

Lo aceptable que es para alguien hacer este tipo de elecciones está influenciado de manera considerable por los regímenes normativos en juego. En algunos contextos sociales, las personas sienten y son consideradas por otros como incompletos si no forman parte de una familia o grupo específico. Una mujer del estado de Gujarat en India, por ejemplo, me señaló (2007) que sus decisiones nunca serían comprendidas fuera del contexto de su familia -que sus acciones reflejarían a su familia, de manera positiva o negativa, hasta el día de su muerte. Un tipo similar de economía moral transnacional influye en las opciones de matrimonio de los jóvenes, elecciones de estilo de vida, posibilidades ocupacionales y el nivel de recursos que tienen para llevar a cabo sus planes de vida individuales y colectivos. Debido a que el arraigo social es tan fuerte y denso, las personas no pueden tomar decisiones basadas en sus propios intereses sin el riesgo de ser excluidas del grupo (Portes y Sessenbrenner, 1993).

Tomemos el ejemplo de Moreno, un hombre de mediana edad que regresó de los Estados Unidos a su pueblo dominicano para abrir una pequeña fábrica de cemento. Sus vecinos lo criticaron de forma enfática cuando contrató a los mejores trabajadores en lugar de a sus parientes y amigos. Críticas similares debió enfrentar un empresario paquistaní que comenzó una compañía de software en Boston. Sus amigos y familiares en Karachi también tuvieron mucho que decir cuando decidió no contratar a ningún conocido lejano que lo buscara por trabajo. Lo mucho que cada hombre podía cambiar su comportamiento económico estaba culturalmente limitado por estas consecuencias sociales (Levitt, 2007).

Los cambios en las relaciones de género son otro campo en el que operan los regímenes culturales. En Karachi, la mayoría de las mujeres no van a la mezquita a rezar; en Boston, no solo oran, sino que también dirigen de forma activa las labores culturales y educativas de la mezquita. Debido a que la mezquita también es un centro sociocultural, las mujeres son necesarias para servir como maestras, administradoras y consejeras, roles que nunca hubieran desempeñado en Pakistán. El repertorio cultural cambia, pero tiene un límite. Las mujeres oran con los hombres, pero no a su lado. En Karachi, también ocurren transformaciones, pero dentro de parámetros aún más limitados. En las entrevistas que realicé con familiares y amigos de inmigrantes en Boston, descubrí que, si bien la mayoría de las mujeres conocía estos cambios, no todas los "tomaban" (Levitt, 
Peggy Levitt. Una mirada transnacional.

Autoctonía Revista de Ciencias Sociales e Historia, Vol. II, Nº1

2007). Algunas mujeres insistieron en que era "su privilegio especial" orar en casa, mientras que otras querían inventar formas de orar y estudiar de forma conjunta con otras mujeres.

Sommer (2005) y sus colegas conceptualizan la cultura como agente. La investigadora argumenta que el arte tiene la capacidad de "interrumpir" o "desbloquear" hábitos. Desestabiliza los regímenes a través de la "desfamiliarización" o la sorpresa inspirada en nuevas técnicas o encuentros artísticos. El compromiso cultural empuja a los actores fuera de sus zonas de confort y formas tradicionales de hacer y pensar y, por lo tanto, puede conducir a un cambio social positivo $\mathrm{y}$ con un propósito. Según Sommer, todos somos agentes culturales, ya que los pequeños cambios en la perspectiva y la práctica pueden convertir a los artistas, los maestros y los líderes religiosos y comunitarios en catalizadores del cambio colectivo. No se trata de si ejercemos como agentes, sino de cuán conscientemente lo hacemos, con qué fin y con qué efecto.

En todo el mundo, los ámbitos creativos han sido durante mucho tiempo vehículos para la agencia. Sin el "Teatro Campesino" no habría existido un Sindicato Unido de Trabajadores Agrícolas, según argumentan los organizadores sindicales que trabajaron con César Chávez. Desde la parte posterior de las camionetas, los altavoces llamaban a los recolectores para que vieran y se unieran a las obras de teatro, en donde se burlaban de los patrones y homenajeaban la solidaridad de los trabajadores. Por otro lado, en el Foro Social de Gujarat en la India, una ONG de derechos sexuales lanzó su campaña con una obra de teatro callejera, una forma de arte familiar en la India, sobre los hijras, hombres biológicos castrados que en el fondo se consideran mujeres. Muchas personas piensan que los lugares donde viven los hijras son puros y, por lo tanto, lugares de justicia. En la obra de teatro, los trabajadores de derechos humanos de la ONG compartieron información sobre Shikhandi, un gran guerrero de la épica Mahabharat a quien se le permitió sentarse junto al dios Krishna para honrar su valentía. Algunas personas creen que Shikhandi era impotente, mientras que otros afirman que era homosexual, sin embargo, independiente de lo que uno crea, sin dudas fue un gran guerrero (Rajaram y Zakaria, 2009). Esta obra reveló a los miembros de la audiencia que la aceptación de las relaciones entre personas del mismo sexo no es meramente una importación occidental sino algo con profundas raíces indias. Los facilitadores presentaron nuevas ideas sobre la homosexualidad utilizando palabras en inglés, que luego las explicaron por medio de elementos familiares de pinturas, bailes y epopeyas.

El ejemplo de la banda del pueblo en México también es útil en este ámbito. La banda no solo es importante durante la fiesta patronal, también es una parte integral del duelo colectivo cuando alguien fallece. Los auditores también experimentan su comunidad de manera diferente cuando reconocen los cambios en la música, porque los no inmigrantes han reemplazado a los músicos que ahora viven en los Estados Unidos $\mathrm{y}$, además, porque se han importado nuevos estilos musicales e instrumentos. La incorporación de elementos nuevos les indica que algo ha cambiado, que quién y qué es la comunidad se ha expandido de alguna pequeña manera. De igual forma, cuando las comunidades piden a los músicos de los pueblos vecinos que reemplacen a sus miembros migrantes ausentes, los vecinos cooperan allí donde pudieron haber competido en el pasado.

Pero la cultura también se trata de ganancias. Ni los intereses económicos subyacentes que dan forma a las representaciones culturales ni los beneficios económicos que se derivan de ellos pueden pasarse por alto. Los mercados creados por la migración transnacional se basan en mercados étnicos y de 
Peggy Levitt. Una mirada transnacional.

Autoctonía Revista de Ciencias Sociales e Historia, Vol. II, Nº1

nostalgia ya bien desarrollados. Una fiesta patronal exitosa requiere vestuario, instrumentos, recuerdos y comida. Incluso los lugares se califican y se venden. Uno de los santuarios religiosos de más rápido crecimiento en México, por ejemplo, es Santa Ana de Guadalupe, en el estado de Jalisco, que se cree es el lugar de nacimiento del patrono de los migrantes de México, San Toribio. No fue el desarrollo económico lo que transformó a este antiguo remanso en una próspera comunidad, sino que los muchos turistas que realizan peregrinaciones allí cada año (Levitt, 2007).

El potencial de ganancia no se pierde en el Estado. Los gobiernos producen sus propias versiones de la tradición para el consumo público y la difusión mundial, que a menudo difieren significativamente de la cuenta de la comunidad. La Chilena, considerada en su origen como una danza de los pobres, se volvió legítima y rentable después de que el gobierno mexicano se apropió de ella (Revilla López, 2000). El Estado impulsó un espectáculo turístico comercial, mostrando el esplendor de México a sus residentes urbanos y extranjeros. En contraste, Grupos Chilenos y tecnobandas usaron la forma para invocar un fuerte sentido de pertenencia entre los mixtecos. Debido a que las Chilenas no consisten en un conjunto fijo de elementos, los músicos podrían incorporar nuevos instrumentos y ritmos, produciendo una autorrepresentación nacional alternativa más allá del alcance del estado.

Los productos culturales tales como bailes, música y transmisiones de radio se crean dentro del contexto de procesos y regímenes culturales que influyen de manera importante en cómo se desarrollan y el impacto que tienen. La "fiesta patronal" se reinventa de forma tal que los actores menos poderosos, como las mujeres o los miembros más pobres de la comunidad, asumen posiciones de poder y reemplazan a las personas que han emigrado. Sin embargo, a quién se le permite hacerlo está fuertemente influenciado por los regímenes culturales sobre lo que es apropiado. La Chilena representa un tipo diferente de trabajo simbólico ahora que incorpora elementos del norte y porque ha sido "ungido" por el Estado mexicano. En esta situación nuevamente los regímenes de poder determinan con fuerza cómo se despliegan los productos culturales y en beneficio de quién. Al no integrarlos en las relaciones sociales y las jerarquías de poder en las que se producen y utilizan, no se explota una posible herramienta de desarrollo y tampoco se reconocen potenciales obstáculos.

La última pieza de este rompecabezas es la circulación cultural, o la relación entre personas que emigran y productos culturales migratorios. ¿De qué manera el movimiento de los cuerpos también involucra el movimiento de ideas, prácticas, imágenes y símbolos, y cómo esto, a su vez, permite un movimiento posterior? Cuando las personas se mudan, ¿qué tipo de productos culturales viajan con ellos? ¿Cómo se transforman mientras viajan y por qué? ¿Cómo influyen el poder, los intereses y las redes sociales en la producción y el consumo cultural global?

Esas preguntas no solo reflejan los esfuerzos recientes para devolver la cultura a los estudios de migración, sino que también un cambio en los estudios de globalización que se alejan de sus entendimientos, basados en escalas descendentes, de la producción cultural global. La migración es una de las fuerzas que impulsa la globalización cultural, fenómeno que ocurre en todos los niveles de la experiencia social. Al unir estos dos diálogos, podemos comenzar a comprender cómo se produce, disemina y consume localmente la cultura global y el por qué de ello.

Investigadores de todas las áreas de las humanidades y las ciencias sociales afirman que la globalización cultural está en funcionamiento, pero rara vez especifican cómo se lleva a cabo de forma real o cuestionan las geografías dentro de las cuales ocurre. Los teóricos de Sistemas Mundiales, NeoInstitucionalistas y académicos de 
Peggy Levitt. Una mirada transnacional.

Autoctonía Revista de Ciencias Sociales e Historia, Vol. II, Nº1

Estudios Globales afirman el alcance creciente de la cultura integral, pero por lo general tratan estas normas y valores como si su intensidad, amplitud y frecuencia se sintieran de igual forma en todas partes. Más análisis de micronivel, aunque prestan mucha atención a contextos sociohistóricos particulares, a menudo no llegan a conectar lo "local" con otras escalas y niveles de experiencia social. Finalmente, investigadores como Howard Becker, David, Halle, Wendy Griswold o Diane Crane, cuyo trabajo sobre las relaciones socioeconómicas subyacentes a la producción cultural también proporciona importantes recursos para este diálogo, describen "diamantes culturales" o "mundos del arte" que tienen un alcance nacional o comparan experiencias nacionales supuestamente discretas. $\mathrm{Si}$ bien merecen crédito por ubicar la producción y el consumo artístico en sus contextos sociales, prestan menos atención a los productos mismos y rara vez abordan las fuerzas transnacionales que los conforman.

Lo que necesitamos, al avanzar, es un diálogo interdisciplinario que explique la relación entre las personas migrantes y la cultura, que explore lo que realmente sucede en los mundos del arte transnacional, ya sean las experiencias de artistas y escritores inmigrantes, la transformación de productos culturales a medida que circulan en respuesta a la migración, o el rol de las instituciones culturales y el gobierno en facilitar o bloquear el movimiento. Tomados en conjunto, tal diálogo produciría una explicación más rica y convincente de cómo y por qué se realiza la producción cultural global y cómo y dónde está implicada la migración.

\section{Un caso concreto}

Un ejemplo de los desarrollos teóricos que ya se están llevando a cabo y que exploran la intersección entre las personas migrantes y la cultura es la investigación sobre remesas sociales. En mi libro del año 2001, The Transnational Villagers, acuñé el término remesas sociales para llamar la atención sobre el hecho de que los inmigrantes envían a sus hogares más que dinero. Observé al menos cuatro tipos de remesas sociales (normas, prácticas, identidades y capital social) que circulan entre Boca Canasta, un pueblo de la República Dominicana, y Jamaica Plain, un barrio de Boston, donde se asentaron muchos Boca Canasteros.

Las remesas sociales circulan de varias maneras: cuando los migrantes vuelven a vivir o visitan sus comunidades de origen; cuando los no inmigrantes visitan a sus amigos y familiares en un país receptor; o cuando los dos grupos intercambian cartas, videos, correos electrónicos, publicaciones en blogs y llamadas telefónicas. Las remesas sociales sobre género, política y religión, entre otros temas, son distintas, pero refuerzan y se fortalecen con otras formas de circulación cultural global, como los valores y comportamientos a los que las personas están expuestas cuando navegan por Internet o miran televisión.

Si bien la idea de las remesas sociales ha ganado cierto terreno en la literatura, no deja de tener críticas. Se argumenta que lo "social" también debe incluir lo "cultural" y que las remesas sociales no se mueven en una sola dirección. También advierten sobre la visión de ellas como siempre positivas, acuerdo que plasmo en este ensayo. Para abordar estas críticas y avanzar en los debates teóricos, he continuado estudiando las remesas sociales y, junto con mi colega Deepak Lamba-Nieves (Levitt y Lamba-Nieves, 2011), las hemos redefinido de la siguiente manera.

\section{Las remesas sociales circulan}

Las ideas y experiencias que los migrantes traen consigo influyen en gran medida sobre quiénes y a qué 
Peggy Levitt. Una mirada transnacional.

Autoctonía Revista de Ciencias Sociales e Historia, Vol. II, Nº1

están expuestos y con quién interactúan en los países donde se instalan. Estas circunstancias afectan las remesas sociales enviadas por los migrantes.

Algunos migrantes, por ejemplo, provienen de comunidades con fuertes tradiciones de participación, ya sea en organizaciones religiosas, manejo de tierras comunales y planes agrícolas, o clubes deportivos. Es natural para ellos reorganizarse colectivamente cuando se mueven, y lo hacen con gran habilidad y conocimiento.

Cuando las personas del pueblo dominicano de Boca Canasta recrearon su liga de béisbol en Boston, por ejemplo, no solo entraron en contacto con otros jugadores y aficionados inmigrantes y nativos, sino que también tuvieron que aprender a negociar el sistema de parques municipales y a obtener permisos para la celebración de eventos de recaudación de fondos. Por el contrario, los migrantes indios del estado de Gujarat en los Estados Unidos transladaron organizaciones religiosas altamente desarrolladas y jerárquicamente organizadas que proporcionaron fuertes apoyos sociales, pero tuvieron pocos contactos con sus vecinos nativos o con la ciudad y el gobierno estatal.

Las ideas y habilidades que cada grupo envió a casa diferían marcadamente. En el caso de Boca Canasta, los migrantes alentaron a sus contrapartes no inmigrantes a adoptar el mismo tipo de cronograma organizado para los campos de juego y las instalaciones que habían utilizado en Boston. Querían que los constructores y las empresas de catering volvieran a sus casas para firmar contratos y respetar los plazos, de la misma manera que veían a los proveedores de alimentos y bebidas rendir cuentas en Estados Unidos. La comunidad de Gujarati, por el contrario, enfatizó la importancia de la educación religiosa formal para los niños, que se había convertido en una prioridad en una nación de mayoría cristiana. Enviaron a India modelos para organizar la educación religiosa y cuál debería ser su contenido.

\section{Las remesas sociales son positivas y negativas}

No todas las ideas y prácticas que los migrantes envían a sus países de origen son positivas. Hay costos y beneficios.

Muchos trabajos académicos sugieren que las remesas sociales agitan las dinámicas de género y las generacionales de manera que benefician a las mujeres. Los hombres y las mujeres migrantes que trabajan y comparten la responsabilidad de la limpieza y el cuidado de los niños hablan y modelan un tipo diferente de relaciones de género cuando visitan o regresan a sus comunidades de origen (De Haas, 2007; Osella y Osella, 2000).

El escritor Amitav Ghosh (1992), por ejemplo, descubrió que los egipcios rurales que habían emigrado a Iraq enviaron ideas y creencias que desafiaron la jerarquía del estatus del pueblo y permitieron una mayor movilidad social. El antropólogo Gunvor Jonsson (2007) descubrió que las personas que se mudaban a la ciudad desde los asentamientos urbanos de la zona rural de Malí presentaban nuevos patrones y deseos de consumo, desde ropa hasta música y comida, y diferentes ideas sobre romance, democracia y cultura juvenil.

Las remesas sociales también influyen en los resultados de salud, según una investigación que realicé junto a Lamba-Nieves. Debido a que en Estados Unidos los Boca Canasteros habían ganado más dinero y recibido más educación, se volvían más conscientes de su salud. Tenían más probabilidades de beber agua embotellada, mantener a los animales fuera de los espacios de vida y reconocer la importancia de los chequeos anuales, porque tenían derecho a uno a través de su seguro médico en los Estados Unidos (Levitt y Lamba-Nieves, 2011). 
Peggy Levitt. Una mirada transnacional.

Autoctonía Revista de Ciencias Sociales e Historia, Vol. II, Nº1

El conocimiento sobre la anticoncepción también llegó a los no inmigrantes en las zonas rurales de Guatemala; esto fue enviado tanto por los familiares de los migrantes y sus amigos en Estados Unidos como por las personas que se mudaron a las ciudades de Guatemala. Los demógrafos David Lindstrom y Elena Muñoz-Franco (2005) notaron que el conocimiento de los métodos anticonceptivos era un fuerte predictor de su uso.

Las actitudes hacia la educación también pueden cambiar. A medida que más jóvenes de Boca Canasta completaron la escuela secundaria y pasaron a la educación superior en Estados Unidos, sus pares no inmigrantes también quisieron ingresar a la universidad. En la comunidad de Gujarati, cuando los jóvenes se aventuraron en una gama más amplia de carreras, se hizo más aceptable estudiar humanidades y relaciones internacionales en lugar de solo finanzas, medicina o farmacología.

Las remesas sociales también pueden desafiar las ideas de las personas sobre la democracia y el estado de derecho. El politólogo T. F. Jiménez (2008) descubrió que la migración transformó la política local mexicana. Más inmigrantes y no inmigrantes participaron de la política y el equilibrio de poder entre los actores de esta área cambió, aunque con efectos duraderos limitados debido a intereses ya arraigados. Los migrantes que retornaron a Governador Valadares en Brasil tenían mucho que decir sobre los políticos y abogados brasileños sobre la base de sus experiencias en Estados Unidos. "Tenemos una democracia en Brasil", señaló Gilberto, de 65 años, "pero no funciona como debería. Tienes un sistema de controles y equilibrios allí ", cada vez que se apagaba el alumbrado público o no se recogía la basura, Gilberto visitaba el ayuntamiento. "Aprendí esto en Estados Unidos: que los gobiernos pueden hacer lo que se supone que deben hacer y que los ciudadanos deben asegurarse de que eso suceda.
Estoy tratando de hacer que la gente entienda que no tienen que aceptar negocios como de costumbre".

Finalmente, los profesionales y emprendedores de tecnología de punta de Pakistán y la India no solo envían nuevas tecnologías y habilidades, sino también ideas sobre la realización de negocios. Trabajar en Estados Unidos ha animado a algunos a correr riesgos, a pensar de manera innovadora y desafiar a un superior en lugar de aferrarse a él. "Lo primero que mi jefe me enseñó cuando llegué a los Estados Unidos", dijo Amir, un ingeniero de 35 años de Karachi, "fue a no levantarme cuando entraba en la habitación o llamar a todos 'señor"'. Si bien la deferencia y la obediencia pueden funcionar en el hogar, Amir se dio cuenta de que las empresas estadounidenses valoraban la individualidad y la innovación.

De ninguna manera, no obstante, todo lo que los migrantes envían es positivo. Tanto los individuos como los líderes comunitarios a menudo hablan sobre su temor de que los inmigrantes importen valores que debilitan a las familias, deifican el consumismo y fomentan la permisividad sexual. Los migrantes y no inmigrantes en el Caribe y América Central también están preocupados por los residentes que son deportados después de participar en actividades delictivas en Estados Unidos. Numerosos residentes y funcionarios locales argumentan que traen malos hábitos, dan un mal ejemplo a la juventud local, comprometen la reputación de los inmigrantes en el extranjero e importan nuevas tecnologías delictivas y contactos con organizaciones internacionales de este tipo. Las personas asiáticas residentes y no residentes consideran a los migrantes como responsables de la creciente popularidad del hinduismo fundamentalista en la India y el islam en Pakistán. Esto no solo se debe al dinero que los migrantes donan, sino también a las creencias y estilos religiosos más conservadores que adoptan e importan una vez que se mudan a Occidente. 
Peggy Levitt. Una mirada transnacional.

Autoctonía Revista de Ciencias Sociales e Historia, Vol. II, Nº1

Las remesas sociales también pueden contribuir a una "cultura de la migración" que hace que el movimiento sea casi inevitable, porque las personas ya no están satisfechas con las oportunidades económicas y sociales que ofrecen sus patrias. Esto es cierto en las comunidades de América Latina y Asia, pero también en lugares como Irlanda, donde a pesar de la década del rugiente "tigre celta", los jóvenes aún emigran porque los hábitos y los ritos de siglos pasados perduran en su comunidad.

Más aún, lo que primero parece ser un desarrollo positivo puede tener efectos indirectos negativos. Un migrante dominicano, por ejemplo, que quería construir un complejo de viviendas en su país, se comprometió firmemente a hacerlo de acuerdo con las normas y códigos de construcción para que no se convirtiera en un "barrio bajo" de edificios mal construidos. La idea, dijo, provino de los proyectos de construcción y los contratos de venta que observó en Estados Unidos. Sin embargo, imaginaba una comunidad cerrada que solo atraería compradores exclusivos y bien educados. Aunque promovió un enfoque ordenado y planificado para el desarrollo, también exacerbó la estratificación de clases que ya había empeorado debido a la migración.

\section{Remesas Sociales Colectivas}

La mayoría de los ejemplos entregados hasta este punto involucran el intercambio de ideas y comportamientos entre individuos. La investigación reciente sugiere que las remesas sociales también se aprovechan colectivamente. Aquí el foco está en Modebo y Soprovis, dos asociaciones locales (HTAs)[8] con sede en las ciudades vecinas de Boca Canasta y Villa Sombrero, para presentar el caso (Levitt y LambaNieves, 2011).

Las HTAs permiten que los inmigrantes de la misma ciudad o región mantengan lazos y apoyen materialmente sus lugares de origen. A veces los migrantes y los no inmigrantes crean organizaciones separadas, asociándose con el grupo que mejor se adecue a los objetivos específicos del proyecto. En el caso de Modebo y Soprovis, los migrantes y los no inmigrantes pertenecen a la misma organización y trabajan juntos desde sus diferentes direcciones.

Cuando las personas abandonaron República Dominicana, losmiembrosno inmigrantesseleccionaron y administraron la mayoría de los proyectos de la HTAs. A medida que la capacidad de recaudación de fondos de los miembros de Estados Unidos aumentó, los miembros migrantes de ambos grupos comenzaron a diseñar proyectos basados en sus experiencias en dicho país. Estos incluyen el establecimiento de una estación de bomberos con su propio camión, la construcción de instalaciones deportivas, la compra de una ambulancia y la organización de campañas de sensibilización sobre VIH y salud sexual. Los miembros migrantes apoyaron proyectos como el complejo deportivo, porque se habían acostumbrado a este tipo de instalaciones en Boston. Vieron el complejo como una forma de mantener a las familias unidas, ayudar a los jóvenes y fomentar el talento del nuevo béisbol. También deseaban utilizar la instalación durante sus vacaciones en casa, y pudieron convencer a sus contrapartes no inmigrantes del valor de tales esfuerzos. El complejo deportivo, que costó alrededor de 200.000 dólares estadounidenses, es el proyecto más grande que Soprovis ha emprendido.

Al hablar de sus colegas migrantes, el actual presidente dominicano señaló: "Debido a que están en un país desarrollado, están buscando otros tipos de construcciones, edificios, otros complejos deportivos y quieren llevar esas ideas a su comunidad ... Boston siempre ha pensado en grande".

Los líderes de dicha ciudad también propusieron construir un camino pavimentado hacia la instalación 
Peggy Levitt. Una mirada transnacional.

Autoctonía Revista de Ciencias Sociales e Historia, Vol. II, Nº1

deportiva, que se encuentra lejos del centro de la ciudad y una avenida que conduce a la playa cercana, como parte de los esfuerzos para aumentar el turismo en la zona. Este "pensamiento a lo grande" y "perspectiva diferente" surgió repetidamente en las entrevistas.

Los no inmigrantes no solo se convencieron de que esta mentalidad de pensamiento anticipado era buena para el desarrollo, sino que también llegaron a creer que un enfoque más ordenado y resuelto de los proyectos de infraestructura, como la construcción de caminos de acceso, no debería ser sólo una ocurrencia. Los intercambios colectivos de remesas sociales reforzaron el respeto por las normas y leyes que los migrantes habían observado en Estados Unidos y cambiaron las ideas sobre planificación, desarrollo y progreso.

\section{Las remesas sociales colectivas en la práctica}

Finalmente, las remesas sociales, ya sea que se intercambien entre individuos o grupos, no se quedan en el mismo sitio, sino que se extienden a otros ámbitos de la práctica y se amplían a otros niveles de gobernanza. En este caso, utilizo el ejemplo de los inmigrantes en Boston que recaudaron dinero para comprar un camión de bomberos para Villa Sombrero. Pero no fue suficiente para modernizar el enfoque de la ciudad hacia la seguridad pública. Los residentes tuvieron que establecer un comité para entrenar a los bomberos voluntarios, identificar un lugar que pudiera servir como su estación y encontrar un sitio para guardar el vehículo de manera segura. Más importante aún, tenían que encontrar una forma de pagar por el equipo y la mano de obra. Debido a que los miembros de las HTAs en Boston no estaban dispuestos a financiar estos esfuerzos de forma indefinida, comenzaron a presionar a los funcionarios del gobierno para que asumieran parte de la carga del apoyo, ante lo cual el alcalde finalmente estuvo de acuerdo.

Por lo tanto, la generación de un proyecto de migrantes se convirtió en un esfuerzo conjunto entre el Estado y la ciudadanía que redefinió las responsabilidades estatales y la de los grupos comunitarios. Conjuntamente, el proyecto fue más allá de la seguridad pública para mostrar cómo el Estado podría asociarse con la comunidad para proporcionar una gama de servicios. Los miembros de la comunidad ahora están buscando tipos similares de acuerdos de distribución de costos con las autoridades municipales y provinciales en materias de salud y educación.

Este tipo de valores y habilidades también se amplían. Cuando realicé el trabajo de campo original, muchas de las personas con las que hablé no consideraban al Estado como responsable de proporcionar servicios básicos, como, por ejemplo, la atención de salud y seguridad pública, porque veían al gobierno demasiado abrumado por muchas otras tareas. Ahora, los migrantes de la República Dominicana ven estas actividades como una parte integral de la buena gobernanza. Cuantas más personas adopten esta postura, estas remesas sociales podrán escalar a niveles más altos de gobierno.

\section{Conclusión}

Este artículo es un llamado para incorporar el espacio y la cultura de manera más central y creativa en los debates sobre migración. Es un llamado para que los académicos y los encargados de la formulación de políticas que se preocupan, de manera principal, por la integración de los inmigrantes en los países de acogida y los que trabajan en el desarrollo del país de origen se vean a sí mismos como parte del mismo diálogo. Finalmente, es un llamado a todos los que quieran usar un lenguaje que posibilite la investigación interdisciplinaria y la formulación de políticas públicas. 
Peggy Levitt. Una mirada transnacional.

Autoctonía Revista de Ciencias Sociales e Historia, Vol. II, Nº1

Los procesos, regímenes y productos culturales informan claramente el nexo entre la migración y el desarrollo de la pobreza de los inmigrantes. La forma en que las comunidades se perciben a sí mismas, lo que quieren, a quién se le permite definir estas metas y cómo intentan lograrlas está culturalmente delimitada. La cultura habilita y restringe las posibilidades. Al no factorizar a la cultura en la ecuación desarrollomigración, los responsables de crear las políticas públicas pasan por alto tanto oportunidades importantes como los posibles obstáculos.

Las investigaciones futuras deben analizar de forma más cuidadosa y sistemática cómo viajan las ideas y los valores y en qué circunstancias el cambio de ideas contribuye a la modificación del comportamiento. Cuando se dan cambios en el nivel local, en las relaciones de género, por ejemplo, ¿se podrían producir también cambios a una mayor escala, como en el comportamiento reproductivo y la participación en el mercado de trabajo? ¿Cuál es el marco de tiempo para que esto ocurra? ¿Bajo qué circunstancias la construcción de la capacidad democrática a nivel local puede ampliarse de manera tal de producir una gobernanza provincial y nacional más fuerte?

Existe una clara división entre los investigadores más interesados en lo que les sucede a los inmigrantes una vez que llegan a un lugar nuevo y aquellos más interesados en lo que sucede en los lugares de donde provienen. Esta es una dicotomía falsa. Estos procesos nunca han estado desconectados, y ciertamente no lo están hoy. Seguir hablando de ellos y organizar investigaciones en torno a ellos por separado es contraproducente. Reifica una separación artificial que no refleja la vida de los migrantes ni nos permite responder creativamente a los desafíos que enfrentan.

Muchos académicos y legisladores ven las remesas económicas como la próxima panacea del desarrollo. Los migrantes claramente hacen importantes contribuciones al desarrollo de la comunidad. Sin embargo, preocupa que, a pesar de la mejora de las condiciones de vida y la infraestructura, esos proyectos carguen de manera desproporcionada a los migrantes y los responsabilicen a ellos por las funciones que legítimamente pertenecen a los estados. Si bien las remesas contribuyen significativamente al desarrollo económico y la supervivencia familiar, también imponen una tremenda carga a quienes las envían. Los vínculos familiares y de parentesco, si bien son una fuente de apoyo social, también pueden ser una fuente de obligaciones interminables. Dichas demandas pueden funcionar contra la movilidad social de los migrantes en el país de acogida y también dificultan la acumulación de capital para el retorno o la inversión en el país de origen. Las políticas de desarrollo impulsadas en las remesas fijan falsa e injustamente las perspectivas de mejora futura sobre las espaldas de los migrantes, lo que plantea preocupaciones tanto a corto como a largo plazo.

Las agencias de desarrollo deben cuidar que su enfoque renovado en las diásporas y las remesas no imponga un estrés adicional a los grupos ya vulnerables. Una forma de salir de este acertijo sería crear capacidad, fortalecer las organizaciones y aumentar las habilidades de manera tal que los migrantes puedan proteger sus intereses de manera más efectiva y que los no inmigrantes estén mejor equipados para tratar con los migrantes en un campo de juego lo más equitativo posible. Otra estrategia incluiría el fomento de la cooperación entre grupos de base para que las comunidades puedan trabajar de manera cooperativa, sin dejar a ninguna comunidad agobiada o excluida de manera desproporcionada.

Espero sobre todo que lo que se ha plasmado aquí conduzca a diálogos interdisciplinarios más verdaderos con economistas y politólogos. Existe un aprendizaje importante en este ensayo. Los científicos sociales 
orientados social y culturalmente tienen que presentar argumentos que sean comprensibles y convincentes para las personas que trabajan fuera de sus disciplinas. Si la investigación futura puede mostrar, tal como aquí se ha indicado, que los cambios culturales en las relaciones de género podrían escalar a los cambios en la fertilidad y la salud reproductiva, entonces los demógrafos estarán más convencidos con nuestros argumentos. $\mathrm{Si}$ podemos mostrar cómo estos mismos cambios podrían conducir a una mayor integración femenina en diferentes sectores del mercado laboral, entonces los economistas también podrían escuchar. Pero tales agendas de investigación requieren asociaciones entre disciplinas y diferentes metodologías. El trabajo de traducción es en ambos sentidos.

\section{Bibliografía}

Alba, R., 1990, Ethnic Identity: The Transformation of White America, New Haven, Yale University Press.

Appadurai, A., 2004, "The Capacity to Aspire: Culture and the Terms of Recognition", in Vijayendra Rao and Michael Walton (eds.), Culture and Public Action: A Cross-Disciplinary Dialogue on Development Policy, Palo Alto, California, Stanford University Press, pp. 5984.

Arizpe, L., 2004, "The Intellectual History of Culture and Development Institution", in Vijayendra Rao and Michael Walton (eds.), Culture and Public Action: A Cross-Disciplinary Dialogue on Development Policy, Palo Alto, California, Stanford University Press, pp. 163184.

Banfield, E., 1967, The Moral Basis for a Backward Society, New York, Free Press.
Besserer, F., 2003, “Contesting Community: Cultural Struggles of a Mixtec Transnational Community", Ph. D. thesis, Stanford University.

Bloemraad, I., 2006, Becoming a Citizen: Incorporating Immigrants and Refugees in the United States and Canada, Berkeley/ Los Angeles, University of California Press.

Bose, S., 2006, A Hundred Horizons: The Indian Ocean in the Age of Global Empire, London/ Cambridge, Massachusetts, Harvard University Press.

Brettell, C. B., 2005a, “The Spatial, Social, and Political Incorporation of Asian Indian Immigrants in Dallas, Texas", Urban Anthropology, num. 34, pp. 247.

Brettell, C. B., 2004b, "Translocal Flows in the Americas", Bellagio Workshop Report, October 2027, 2004 (Internal Rockefeller Foundation Document).

Bryceson, D. F. and U. Vuorela, 2000, The Transnational Family: New European Frontiers and Global Networks. Oxford/New York, Berg.

Cadge,W.etal.,2009, The Cityas Context:Culture and Scale in New Immigrant Destinations, in Pieter Bevelander (ed.), Malmö, Sweden, Malmö Institute for Studies of Migration, Diversity and Welfare (MIM)/Department of International Migration and Ethnic Relations (IMER) (Willy Brandt Series of Working Papers in International Migration and Ethnic Relations 1).

Chavez, L. R., 2001, Covering Immigration: Popular Images and the Politics of the Nation, Berkeley, University of California Press.

De Haas, H., 2007, Remittances, Migration and 
Social Development: A Conceptual Review of the Literature, Geneva, United Nations Research Institute for Social Development/Social Policy and Development Programme (Paper num. 34).

Eade, John, 1997, Living the Global City: Globalization as a Local Process, London, Routledge.

Fix, M. and W. Zimmerman, 2000, "The Integration of Immigrant Families", Strengthening Immigrant Families and American Communities: Strategies for the New Century, Washington, DC, Urban Institute.

Gans, Herbert, 1979, "Symbolic Ethnicity: The Future of Ethnic Groups and Cultures in America", Ethnic and Racial Studies, vol. 2, num. 1, pp. 120.

García Canclini, N., 1995, Hybrid Cultures: Strategies for Entering and Leaving Modernity, Minneapolis, University of Minnesota.

Ghosh, Amitav, 1992, In an Antique Land, London, Granta Books.

Gil, Rocio et al., 2005, "Informe de investigacion \#1. Etnografía transnacional de Santa María Tindú circuito Oaxaca, subcircuito Mixteca”, unpublished manuscript.

Gilroy, P., 1993, The Black Atlantic: Double Consciousness and Modernity, Cambridge, Massachusetts, Harvard University Press.

Glick Schiller, N., A. Caglar and T. C. Guldbrandsen, 2006, "Beyond the Ethnic Lens: Locality, Globality, and BornAgain Incorporation", American Ethnologist, num. 33, pp. 612633.
Glick Schiller, N. and A. Caglar, 2009, “Towards a Comparative Theory of Locality in Migration Studies: Migrant Incorporation and City Scale", Journal of Ethnic and Migration Studies, vol. 35, num. 2, pp. 177202.

Glick Schiller, N. and P. Levitt, 2006, Haven't We Heard this Somewhere Before? A Substantive Review of Transnational Migration Studies by Way of a Reply to Waldinger and Fitzgerald, Princeton, New Jersey, Center for Migration \& Development, Princeton University (Working Paper 0601).

Godzniak, E. and S. F. Martin (eds.), 2005, Beyond the Gateway: Immigrants in a Changing America, Landham, Maryland, Lexington Books.

Harrison, L. and S. Huntington (eds.), 2000, Culture Matters: How Values Shape Human Progress, New York, Basic Books.

HernándezLeón, R. and Zúñiga, V., 2003, "Mexican Immigrant Communities in the South and Social Capital: The Case of Dalton, Georgia", Southern Rural Sociology, vol. 19, num. 1, pp. 2045.

Huntington, S., 1996, Clash of Civilizations, New York, Simon and Schuster.

Jiménez, L. F., 2008, "De Paisano a Paisano: Mexican Migrants and the Transference of Political Attitudes to their Country of Origin", $\mathrm{Ph}$. D. Dissertation, University of Pittsburgh. Available at: <http://etd.library.pitt.edu/ETD/ available/etd12122008102319/unrestricted/ Luis_F_Jimenez_12_2008. pdf $>$ (last accessed on March 9, 2011).

Jónsson, G., 2007, The Mirage of Migration: Migration Aspirations and Immobility in a 
Malian Soninke Village, Master's thesis, num. 466, University of Copenhagen, Institute for Anthropology.

Keohane, R. O. and J. S. Nye Jr., 1971, "Transnational Relations and World Politics: A Conclusion", International Organization, num. 25, pp. 721748 .

Khagram, S. and P. Levitt, 2007, The Transnational Studies Reader, New York/ London, Routledge Press.

LambaNieves, D., "Furthering the Discussions on the Migration Development Nexus: A Closer Look at Dominican Hometown Associations and their Development Impacts", unpublished paper, mit Department of Urban Studies and Planning.

Lamont, M. and M. L. Small, 2008, "How Culture Matters: Enriching our Understanding of Poverty", in Ann Lin and David Harris (eds.), The Colors of Poverty: Why Racial and Ethnic Disparities Persist, New York, Russell Sage Foundation, pp. 76102.

Levitt, P., 2001, The Transnational Villagers, Berkeley/Los Angeles, University of California Press.

Levitt, P., 2007, God Needs No Passport, New York, The New Press.

Levitt,P. and N. Glick Schiller, 2004, "Conceptual and Methodological Developments in the Study of International Migration", International Migration Review, vol. 38, num. 3, pp. 10021039.

Lindstrom, D. P. and E. MuñozFranco, 2005, "Migration and the Diffusion of Modern Contraceptive Knowledge and Use in Rural
Guatemala", Studies in Family Planning, vol. 36, num. 4, pp. 277288.

Massey,D.S.,2008,NewFacesinNew Places:The Changing Geography of American Immigration, New York, Russell Sage Foundation.

North American Transnational Communities Program (NATC), 2004, "The Cultural Dimension of Transnational Communities", Meeting Report, Oaxaca City, Oaxaca, Mexico, Internal Rockefeller Foundation Document, August 910, 2004.

Osella, C. and F. Osella, 2000, "Migration, Money and Masculinity in Kerala", The Journal of the Royal Anthropological Institute, vol. 6, num. 1, pp. 115131.

Padín, J. A., 2005, “The Normative Mulattoes: The Press, Latinos, and the Racial Climate on the Moving Immigration Frontier", Sociological Perspectives, num. 48, pp. 4975.

Portes, A. and J. Sensenbrenner, 1993, "Embeddedness and Immigration: Notes on the Social Determinants of Economic Action", American Journal of Sociology, vol. 98, num. 5, pp. 13201350.

Portes, A. and R. G. Rumbaut, 2006, Immigrant America: A Portrait, Berkeley/Los Angeles, University of California Press.

Rajaram, N. and V. Zakaria, 2009, "Translating Women's Human Rights in a Globalizing World: The Spiral Process in Reducing Gender Justice in Baroda, India", Global Networks, vol. 9, num. 4, pp. 462485.

Rao, V. and M. Woodcock, 2007, "Global Insights: The Disciplinary Monopoly in 
Development Research at the World Bank", Global Governance, num. 13, pp. 479484.

Reitz, J. G., 2002, "Host Societies and the Reception of Immigrants: Research Themes, Emerging Theories, and Methodological Issues", International Migration Review, vol. 36, num. 4, pp. 10051019.

Revilla López, U., 2000, "La chilena mixteca transnacional", unpublished master's thesis, Mexico, Universidad Autónoma Metropolitana, Iztapalapa Campus, Anthropology Department.

RiveraSánchez, L., 2004, "Expressions of Identity and Belonging: Mexican Immigrants in New York", in Jonathan Fox and Gaspar RiveraSalgado (eds.), Indigenous Mexican Migrants in the United States, La Jolla, California, Center for U.S. Mexican Studies, UCSD, pp. 417446.

Sassen, S., 2001, The Global City, New York/ London/Tokyo, Princeton, New Jersey, Princeton University Press.

Sen, Amartya, 1999, Development as Freedom, New York, Alfred A. Knopf.

Singer, A., S. W. Hardwick and C. B. Brettell (eds.), 2008, Twenty-First Century Gateways: Immigrant Incorporation in Suburban America, Washington, DC, Brookings Institution Press.

Smith,R.,2006,MexicanNew York:Transnational Lives of New Immigrants, Berkeley, University of California Press.

Smith, H. A. and O. J. Furuseth, 2006, Latinos in the New South: Transformations of Place, Burlington, West Virginia, Ashgate Publishing, Ltd.
Sommer, D., 2005, "Art and Accountability", unpublished manuscript.

Swidler, A., 1986, "Culture in Action: Symbols and Strategies", American Sociological Review, num. 51, pp. 273286.

Waldinger, R. G., 2001, Strangers at the Gates: New Immigrants in Urban America, Berkeley, University of California Press.

Waters, M., 1990, Ethnic Options, Berkeley/Los Angeles, University of California Press.

Werbner, P., 2000, "Global Pathways. Working Class Cosmopolitans and the Creation of Transnational Ethnic Worlds", Social Anthropology, vol. 7, num. 1, pp. 1735.

Wilmaladharma, J., D. Pearce and D. Stanton, 2004, "Remittances: The New Development Finance?", Small Enterprise Development Journal, vol. 15, num. pp. 1219.

World Bank, 2009, Migration and Remittances Factbook, Washington, DC, World Bank.

Recibido: 05 de septiembre de 2017

Aceptado: 04 de enero 2018

NOTAS

[1] Artículo publicado originalmente en inglés en: Levitt, Peggy. (2011). "A Transnational Gaze”. Revista Migraciones Internacionales, Vol. $6 \mathrm{~N}^{\mathrm{o}}$ 1, pp. 9-44. Publicado aquí con autorización de la autora, Peggy Levitt y del 
Editor, Eduardo Rodríguez, de la Revista Migraciones Internacionales. Traducido por Daniela Soto y Dr. Juan Eduardo Ortiz López. Traducción revisada por Dra. Carol Chan y Dra. Iskra Pavez-Soto. [Nota del Editor].

[2] Se re iere a la Revista Migraciones Internacionales [N. del T].

[3] Se re iere a la Revista Migraciones Internacionales [N. del T].

[4] El concepto melting pot se puede traducir al español como crisol cultural, crisol multicultural, crisol de "razas" o crisol de culturas [N del T].

[5] El concepto salad bowl se puede traducir al español como una "ensaladera multicultural". Se re iere a la convivencia de varios grupos culturalmente distintos en una misma ciudad, aludiendo a la metáfora de los diferentes ingredientes que se combinan en un bol de ensalada [N. del T].

[6] Los académicos del área de los Estudios Urbanos y Turísticos son socios potenciales para este debate. De hecho, existen dos revistas relativamente nuevas, Mobilities y Tourism Studies que destacan el trabajo que se desarrolla en el área [Nota traducida de la version original].

[7] Se incluye su autorrepresentación, el ethos hacia los inmigrantes, cómo se usa la cultura para promover la renovación urbana y su historia y la economía política [Nota traducida de la version original].

[8] El concepto HomeTown Association se puede traducir al español como asociación local o asociaciones locales. La autora usa la sigla HTAs por sus iniciales en inglés [N. del T]. 